\title{
Correction to: Retractions covered by Retraction Watch in the 2013-2015 period: prevalence for the most productive countries
}

\section{D. Ribeiro ${ }^{1} \cdot$ S. M. R. Vasconcelos ${ }^{1}$}

Published online: 31 January 2018

(C) Akadémiai Kiadó, Budapest, Hungary 2018

\section{Correction to: Scientometrics https://doi.org/10.1007/s11192-017-2621-6}

In the original publication of the article, the name of the second author in Marcus and Oranksy (2014) was misspelled. It should read: Oransky.

Resnik (2009) should read Resnik (2011). The same should be noted in the References.

Martinson et al. (2007) should read Martinson et al. (2005). The same should be noted in the References.

Butler et al (2015) should read Butler et al (2016). The same should be noted in the References.

Academy of Medical Science (2015) should read The Academy of Medical Sciences (2015). The same should be noted in the References. The link to the Symposium Report cited is https://acmedsci.ac.uk/viewFile/56314e40aac61.pdf.

In the text ICMJE (2017) should read ICMJE (2016). The same should be noted in the References.

A $\mathrm{t}$ is missing in Commitee in International Committee of Medical Journal Editors. (ICMJE).

In the References, Lancet should read The Lancet.

The original article can be found online at https://doi.org/10.1007/s11192-017-2621-6.

S. M. R. Vasconcelos

svasconcelos@bioqmed.ufrj.br

1 Science Education Program, Institute of Medical Biochemistry Leopoldo de Meis, Federal

University of Rio de Janeiro, Rio de Janeiro, Brazil 